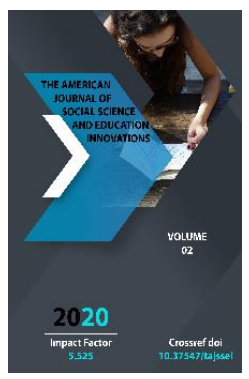

\title{
Imitation Of The Forthcoming: Interposition Approach In Communal Organization
}

\author{
Kambeiz Talebi (PhD) \\ Faculty Member of the University of Tehran, Iran
}

Journal Website:

http://usajournalshub.c

om/index,php/tajssei

Copyright: Original

content from this work may be used under the terms of the creative commons attributes 4.0 licence.

\section{ABSTRACT}

Regarding the unpredictability of communal frameworks and the presence of self-ruling mediates, planning and making the forthcoming requires an uncommon technique, which can fit these components with itself. This can be conceivable by forthcoming portraying, which makes an understanding into the ideal forthcoming, and presents a genuine point of view of it; as well as it advances an arranged impression of the ideal status to force a roused viewpoint to what's to come. In global levels, portraying the forthcoming which is for the most part led by cutting edge nations causes different nations make responses or inverse response which are worldwide and unexpected in different manners, for example, symphonious, latent, turbulent, dynamic and proactive responses. Nonetheless, the primary accomplishment of this conversation is that communal orders must present their very own fitting image forthcoming, which appreciates enough fascination in empower the individuals from applicable communal orders. This image is here and there molded dependent on reproducing an ideal circumstance through the past dreams, or on the norm, and in some cases simply on a viewpoint zeroing in on forthcoming. What makes a difference is that the forthcoming picture must be led on a reasonable and practical premise, for else it might be considered as a beguiling plan, which is outlaw, delicate, and transient due to its infleXibility toward the optimistic advancement of the human communal orders.

\section{KEYWORDS}

Visualization, forecast, forthcoming development, motivation, proactive response, the third wave, the finish of history 


\section{INTRODUCTION}

Subjects of humanities and forecast of conduct of communal frameworks Mankind from past up to now were careful to anticipate what's to come. Perhaps we can say human's motivation of expectation is to diminish vulnerability and improve his circumstance against rivals and other potential dangers. On the off chance that one contrasts humanities' subjects and physical and characteristic sciences he will find that scientists of physical and regular sciences work with simpler and more sensible elements. While expert of sociologies is looked to three significant issues: Dynamics and consistent difference in sub-units of gettogethers Diversity of measurements and states ofthe occasions Presence of a mass of the individuals who make a move selfsufficiently in communal frameworks Therefore, visualization and forecast of conduct of communal frameworks appear to be troublesome; viable and dynamic presence in condition requires foreseeing the conduct of such these frameworks. Readiness to development and advancement in the widespread serious condition rouses people, despite the fact that in a plausible states, to join their creative mind about forthcoming, to investigate an arrangement about it in their psyche, to reprocess, and to change it continually. The fact of the matter is that while human variables are a unique aspect of the occasions that are under his examination; set out to anticipate the conduct of the occasions. This reality causes that his considerations and thoughts (in any event, during the examination) are influenced by his condition (subject ofthe study). Besides, it makes an open door for him as a piece of elements that effect on the examination's subject, to impact upon it and to change conduct of things to come occasions as indicated by his speculations and thoughts. Accordingly, it makes a continuum of thoughts, which are genuinely molded about forthcoming instead of the plans that are intended to force the forthcoming and to reprocess the forthcoming's conditions. Expectation and anticipation in the degree of worldwide relations: By expanding the size and measurements of communal frameworks, their unpredictability gets more prominent than previously. Communal framework is an all out subject, which is usable for suborganization (like two-individuals family) and large scale frameworks, (for example, nations, global organizations and in any event, for the all inclusive framework). Communal framework contains different elements. The subject "forecast" is significant for all of communal frameworks, yet it is intriguing to bring it up in worldwide levels.

We see that familiarity with nature of nearby, cooperator, contender or inverse nations complete; bigly affect activities and mediations of different nations. Subsequently, exploring to anticipate how different nations do is significant for the individuals who plan public procedures. At the point when the motivation behind exploration and study is to look at old status, we need to utilize chronicled contemplates, But when the reason for examination and study is to consider whom are coming, this inquiry is raised that "what direction ought to be utilized to arrive at a response to an inquiry concerning forthcoming?" To respond to the inquiry in any event two different ways are outstanding: 1 . To investigate the substance or'national plans and methodologies and discourses of communal frameworks' pioneers in worldwide levels and to conclude explanation about their objectives. 2. To 
supplant ourselves in skin of the fundamental leaders of different nations and making a situation about their likely mediations.

\section{TROUBLE OF MEDIATION IN COMMUNAL} FRAMEWORKS:

Eminent point is that nations even were prevailing with regards to anticipating the conduct of one another, endeavoring to change unfortunate conduct and to fix alluring conduct, are seen by intervener nations as a major issue. This undertakings were delivered forcibly in past. In any case, because of unsteadiness the authority of tyrant, use of money related assets as a fruitful procedure, was seeing for authority of imperialistic government. Notwithstanding, in infonnation and correspondence time with respect to existing issues with respect to monetary sway, dubious authority is most taking note.

Disintegration of east alliance and disposal the name of Soviet Union from political stylish writing, nothingness the unifier foe of west since parts of interior soundness fonned dependent on the presence of shared adversary and the end of this shared adversary give a foundation to inner war between them. For instance, Afghan warrior bunches in resistance with Soviet Union didn't involve in inward war. Notwithstanding, wiping out the creative mind of unfamiliar ground-breaking adversary began inward war between them until division of Afghan nation. Thusly, planning "conflict of progress" hypothesis can assist with securing the intelligibility of "American-European western civic establishments" coalition and ensure the rationality of American multicultural society, by making an image of new shared adversary in inverse "ConfuCian and Islamic developments" alliance. C. Philosophical authority of liberal west in forthcoming and the finish of history (the liberal finish of history): Francis Fukuyama, American communal expert and political mediator, is one of supporter of political structure of liberal-majority rule government and market free enterprise like style of United States (Heywood 2000, p 293). He accepts that the twentieth century tunicate to last and universalistic win of progressivism. This suspicion requires breaking down everything being equal and significant contenders of market private enterprise (as prudent association establishment) and crumbling of the entirety of decisions and significant contenders of liberal-majority rules system (as political association establishment) (Heywood 2002, p 62). In the perspective on Fukuyama, liberal-majority rules system is the last fonn • of human government. This eminent achievement roots from two components: first: liberal-democrat frameworks are entirely liable, set up differing relative lines among government and individuals, and second, liberal democracy is monotonously related with private enterprise framework that is expansively associated with clients' inclinations and achievement. Worldwide popularity of Fukuyama emerges his paper "the finish of history" that grows it later in "the finish of history " and "the last man" books in 1992; with this case the historical backdrop of political musings and accepts tunicate with recognizing of liberal-majority rules system as the last of human government. He talked about that the connection between financial turn of events and communal lucidness in "trust" and "the extraordinary interruption" books (Heywood 2002, p 31). His accentuation to "the last" and "the end" suggests his incredible enthusiasm to foresee about forthcoming. Beside the discussable and questioning distinctive perusing that safeguard from the rationale of 
liberal-popular government and underscore to practical estimations of interests and assessments of costumers and individuals on the achievement of political and communal association, this earnestness about guesses of forthcoming looks like to touchy prejudices and strong maxims of wearing groups and ideological groups instead of insightful forecast about eventual fate of history and humanity. Obviously, conveying of such these forecasts is exceptionally powerful and instrumental in intriguing or resolve of supporters and disciples. Introducing the assorted picture for differing gathering of human culture: While accurate forecast of communal frameworks appears to be extremely troublesome and unlikely, heaps of tries are seen to introduce an image of forthcoming to human culture, thusly, that the image are gft'ected different interests of human gatherings in different communal orders. It is seen that the imitations dependent on sayings of Nostradamus and something to that effect, appear to be exceptionally agreeable for general house, planned pictures of Toffler and the others like him, recovers their fundamental addressees between the educated people gatherings, columnists, and world's technocrats. While Huntington's hypothesis propels the scholars of political theories and global relations mostly and Fukuyama's hypothesis endeavors to extinguish the thirst of thought practicing in philosophical and political extensions. It is extremely intriguing that with regards to these photos, west is the champ of field or overseeing it and was watchful to key prevalent on world or parades its boss in political way of thinking. Obviously, "the law of essential assortment" is seen to control muddled communal orders and different imitations are accommodated different communal, master, proficient, logical, and philosophical gatherings that are dynamic in world. Subsequently, evidently, all of philosophical, logical, and editorial and even offbeat ways to deal with "forthcoming looking" subject arrive at an extraordinary outcome: the uncontested unrivaled of west and all that has a place with them in all of human communal orders. Endnotes: considering to the need of proactive response in portraying about forthcoming When we need to plan proactive technique, with respect to these pointes appear to be vital:

\section{CONCLUSION}

1. To take this technique, we should not follow the roused depicters bit by bit and should regard to truth sincerely; on the grounds that with respect to authority slow on human communal orders to the idea of enlivened plans, regardless of whether basic emphasis on persuasive forthcoming structure (rather than forthcoming looking genuinely) will convict to crush.

2. We should underscore to the need of loyalty of methodological rules of hypothesis handling like sensible need, situation of closing, provability, revocability, withal restraint from negative fancifulnesses emerge from conviction to paranoid notion or oversimplified musings to adequacy and practical of referenced imitation.

\section{REFERENCES}

1. Bums, J.M. (1978), Marx and modem governmental issues, Barkaz, 1451. 129 Tehran:

2. Doz. Y.Land, Philosophical glossary of Marx, Tehran Nashr-e Barkaz, 1492. 
Doi: https://doi.org/10.37547/tajssei/Volume02Issue09-30

3. Hinings, C.R and Greenwood, (R 1988), "Forecast in legislative issues science, contrasting hard and delicate science SAMT distribution, 1492. 